\title{
Molecular Characterization of Plasmid-Mediated Non-O157 Verotoxigenic Escherichia coli Isolated from Infants and Children with Diarrhea
}

\author{
Md Fazlul Karim Khan ${ }^{1}$ \\ Hassan Maziz
}

\author{
Shah Samiur Rashid ${ }^{*}$. \\ Aizi Nor Mazila Ramli ${ }^{1}$
}

\author{
Mohammad Nazmul ${ }^{2}$ \\ Roesnita Baharuddin ${ }^{4}$
}

\author{
${ }^{1}$ Faculty of Industrial Sciences Technology, Universiti Malaysia Pahang, Gambang, 26300 Pahang, Malaysia \\ ${ }^{2}$ Faculty of Industrial Sciences and Technology, Universiti Malaysia Pahang (UMP,),Gambang, 26300 Pahang \\ Malaysia, \\ ${ }^{3}$ Graduate School of Medicine, Perdana University, Jalan MAEPS Perdana, Serdang, 43400 Selangor, Malaysia \\ ${ }^{4}$ Department of Pathology, Hospital Tengku Ampuan Afzan, 25100 Kuantan, Pahang, Malaysia \\ *Corresponding author: samiur@ump.edu.my \\ *ORCID ID: * https://orcid.org/0000-0003-1109-5706
}

Received 30/8/2019, Accepted 16/2/2020, Published 1/9/2020

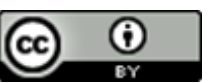

This work is licensed under a Creative Commons Attribution 4.0 International License.

\begin{abstract}
:
A significant increase in the incidence of non-O157 verotoxigenic Escherichia coli (VTEC) infections have become a serious health issues, and this situation is worsening due to the dissemination of plasmid mediated multidrug-resistant microorganisms worldwide. This study aims to investigate the presence of plasmid-mediated verotoxin gene in non-O157 E. coli. Standard microbiological techniques identified a total of 137 E. coli isolates. The plasmid was detected by Perfectprep Plasmid Mini preparation kit. These isolates were subjected to disk diffusion assay, and plasmid curing with ethidium bromide treatment. The plasmid containing isolates were subjected to a polymerase chain reaction (PCR) for investigating the presence of plasmid mediated verotoxin gene (VT1 and VT2) in non-O157 E. coli. Among the $137 \mathrm{E}$. coli isolates, 49 isolates were non-O157 E. coli while $29(59.1 \%)$ isolates were verotoxin producing non-O157 serotypes and 26 non-O157 VTEC isolates possessed plasmids. Certain isolates harboured single sized plasmid while others had multiple plasmids with different size varied from $1.8 \mathrm{~kb}$ to 7.6kb. A plasmid containing all (100\%) the isolates was multidrug-resistant. Eight isolates changed their susceptibility patterns while three isolates were found to lose plasmid after post plasmid curing treatment and the rest of the isolates (15) remained constant. Different PCR sets characterized 3 plasmid-mediated verotoxins producing non-O157 E. coli. This current study demonstrated the occurrence of plasmid mediated verotoxin gene in non-O157 E. coli. To the best of our knowledge, this is the first report in the global literature on plasmid-mediated verotoxin gene in non-O157 E. coli. Timely diagnosis and surveillance of VTEC infections should prioritize to stop or slow down the virulence gene for dissemination by plasmidmediated gene transfer amongst the same bacteria or other species.
\end{abstract}

Key words: Diarrhea, Malaysia, Non-O157 E. coli, Plasmid, Verotoxin.

\section{Introduction:}

In recent times, the exhibition of multidrugresistance by bacteria has continued to establish a significant public health problem that is yet to be overcome. The occurrence, spread, and persistence of antibiotic resistance in bacteria by various contributory factors are poorly understood (1). Escherichia coli (E. coli) was listed to be a cause of serious infection in a community setting (2) and Shiga toxin-producing $E$. coli (STEC) known as verotoxin-producing $E$. coli (VTEC) has emerged as a pathogen that causes numerous risk to public health (3). VTEC, virulent groups of bacteria allied with mild diarrhea to severe bloody diarrhea among the children and infants (4). O157: H7 VTEC serotype associated with human outbreaks and nonO157 VTEC serotypes has been identified for several human illnesses (5). In general, the most outbreaks of human infections by VTEC occur through the ingestion of contaminated foods or water, vegetables, fruits, undercooked meats, unpasteurized milk, and dairy products. Direct 
animal contacts or environmental factors can also cause infections (2).

Currently, among the numerous environmental and genetic factors; plasmid has carried the resistant properties against multiple drugs in bacteria while different resistance genes transfer to a sensitive counterpart (6). Plasmids play an essential role in disseminating bacterial resistant properties among the same or different clinical pathogens by conjugation (7). These conjugative plasmids are indeed spread antibiotic resistance in bacterial families; Enterobacteriaceae, and Enterococcaceae (8). This resistance to antibiotics occurs in bacteria through chromosomal mutation and acquiring genetic materials by plasmids. Generally, plasmidbacterium creates superbugs and disperse in clinical settings, especially in nosocomial pathogens (9). A wide range of plasmids carrying multidrug-resistant (MDR) genes are easily transmissible to sensitive bacterial species and causes a major medical problem (10). Moreover, multiple plasmid-mediated resistance mechanisms have been increasing in many bacteria, thus resulting in diagnostic and therapeutic challenges. Also, such developed resistance can make sensitive pathogens resistant to multiple antibiotics. Consequently, the treatment of infections becomes more difficult and at times almost unmanageable. Therefore, antibiotics are essential to support therapy in modern medicine for the treatment of infectious diseases. However, widespread and misuse of antibiotics has spread resistant mechanisms towards different antibiotics (11-13). Besides, antibiotic susceptibility of bacterial strains is not constant, but vigorous and changes with period and environment (14). As a result, more people die from resistant infections every year. Unfortunately, the discovery, development of antibiotics, and inappropriate usage of antibiotics have led to the rapid existing of antibiotic-resistant isolates across the world. Understanding the molecular epidemiology of resistant plasmids have been complex due to diversity and dynamic characteristics. Meanwhile, identification of the infection sources could be a key-point step towards decreasing the prevalence of variants pathogen as well as reducing the risk, prevent, or treat infections. Consequently, it is essential to survey the prevalence of plasmidmediated genes in hospital settings, which might influence physicians to choose a broad-spectrum antimicrobial agent. This scenario provoked us to determine and characterize the verotoxin gene (VT) genes in non-O157 E. coli among young infants and children in Kuantan, Malaysia, and shed light on the phylogenetic similarity index, virulence gene profiles, and the sequence analysis.

\section{Materials and Methods: \\ Samples types, sources and study sites}

In this study, $137 \mathrm{E}$. coli isolates were obtained from fecal samples. Isolates were assessed for the existence of virulence genes associated with diarrhea. These isolates were obtained from children below 5 years old at Tengku Ampuan Afzan Hospital, Kuantan, Malaysia, from September 2018 to April 2019. All the clinical isolates were plated on MacConkey agar (Oxoid, United Kingdom) and incubated at $37^{\circ} \mathrm{C}$ for 24 hours under aerobic conditions.

\section{Plasmid isolation and profiling}

Perfectprep Plasmid Mini preparation kit (Eppendorf, Germany) was used to extract plasmid DNA according to the manufacturer's instructions without any modification. After purification, the molecular weight of plasmid DNA was determined and compared with supercoiled DNA 2 to $10 \mathrm{~kb}$ ladder (Promega, USA) (15). Electrophoresis of the DNA was carried out at 80 volts on a $1.5 \%$ agarose gel for 60 minutes (16).

\section{Phylogenetic analysis based on antibiotic susceptibility}

All the plasmid positive non-O157 VTEC isolates were subjected to susceptibility test by the disk diffusion antimicrobial assay of Kirby-Bauer (17) and the phylogenetic relatedness was generated using "unweighted pair group average (UPGMA) algorithms" of PAST.

\section{Plasmid Curing}

A plasmid containing non-O157 VTEC strains were subjected to curing according to Zaman et al., (18) but with modifications. Ethidium bromide $125 \mu \mathrm{g} / \mathrm{ml}$ was selected as a curing agent, cure plasmids successfully at a higher rate. Amoxicillin-resistant non-O157 VTEC isolates were used as selective marker and isolates containing plasmids were subjected to curing treatment. Each of the organisms was overnight cultured in nutrient broth (NB) solution containing amoxicillin at $37^{\circ} \mathrm{C}$ aerobically and diluted to $10^{4}$ cells/mL with freshly prepared nutrient broth by serial dilution methods and the optical density was checked using the spectrophotometer. From each of the diluted samples, $0.5 \mathrm{~mL}$ dilution was added to $4.5 \mathrm{~mL}$ of nutrient broth containing $125 \mu \mathrm{g} / \mathrm{ml}$ ethidium bromide to form the concentration of $10^{3}$ cells $/ \mathrm{mL}$. The resulting sample was then incubated aerobically at $37^{\circ} \mathrm{C}$ in an orbital shaker at $150 \mathrm{rpm}$ for 48hours. After incubation, the post 48 hour's growth was diluted to $10^{3}$ cells $/ \mathrm{ml}$ with normal saline and $1 \mathrm{ml}$ of the dilution from each sample 
isolate was plated on Mueller Hinton agar for overnight incubation at $37^{\circ} \mathrm{C}(18)$.

Antibiotic susceptibility post plasmid curing

After the post plasmid curing, the amoxicillin-susceptible, lactose-fermenting, and indole-positive colonies have lost their plasmid(s); These isolates were considered as cured (mutant) $E$. coli. All the cured strains were subjected to susceptibility test by the disk diffusion antimicrobial assay of Kirby-Bauer (17). Obtained cured colonies were spread out on Mueller Hinton agar plates containing Amoxicillin- AMX, Cefalexin -CEX, Imipenem-IPM, CiprofloxacinCIP, Amikacin- AMK, Aztreonam- ATM antibiotic disks. After the aerobic incubation at $37^{\circ} \mathrm{C}$ for $24 \mathrm{hrs}$, the zone of inhibition was measured aerobically according to Clinical and Laboratory Standard Institute (CLSI) guidelines (19).

\section{Plasmid-mediated verotoxin gene}

Of the total isolates of non-O157 VTEC, the extracted plasmid was purified to determine the presence of VT genes. Gel purification was done at a lower concentration of $0.7 \%$ agarose gels at 80 volts for 60 minutes. QIAquick Gel Extraction kit was used to isolate the DNA templates from agarose gel according to the manufacturer's guidelines. These DNA templates were used for further studies. The presence of VT gene (VT1 and VT2) in nonO157 E. coli were determined by the polymerase chain reaction (PCR) protocol using two different types of oligonucleotide primers (VT1: F- 5'-CAC CAG ACA ATG TAA CCG CTG-3'; R- 5'-CAG TTA ATG TGG TGG CGA AGG- 3' and VT2: F5'-GCG TCA TCG TAT ACA CAG GAG C-3'; R5'-ATC CTA TTC CCG GGA GTT TAC G-3') (20). During the thermocycling conditions; an initial denaturation step at $94^{\circ} \mathrm{C}$ for $3 \mathrm{~min}$ for one cycle was followed by 35 cycles of denaturation at $94^{\circ} \mathrm{C}$ for $1 \mathrm{~min}$, annealing at $55^{\circ} \mathrm{C}$ for $1 \mathrm{~min}$ and extension at $72^{\circ} \mathrm{C}$ for 2 min and final extension 1 cycle of $72^{\circ} \mathrm{C}$ for $10 \mathrm{~min}$ in an Eppendorf Mastercycler (Eppendorf AG, Hamburg, Germany). The amplified DNA products were separated by electrophoresis on a $1.5 \%$ agarose gel at 80 volts for 60 minutes, stained with $0.5 \mu \mathrm{g} / \mathrm{ml}$ GelRed (Biotium, USA) and examined for DNA under ultraviolet light using gel documentation system (Amersham Imager 680, USA). All the PCR products were purified by QIAquick PCR purification kit (QIAGEN, USA) according to the manufacturer's guidelines and sent for sequencing at Apical Scientific Sdn Bhd Malaysia. Sequences were analyzed using the BLAST program for the nucleotide database and aligned with VT1 and VT2 gene.

\section{Statistical analyses}

A significant level between different groups was defined by Excel add-in Megastat, version 10.1 software (2007) using Chi-squared test and p-value $(\mathrm{p} \leq 0.05)$ was considered significant.

\section{Results:}

Based on gel electrophoresis, non-O157 VTEC strains showed the occurrence of multiple bands with varying size in DNA plasmid.

Among the 137 E. coli isolates, 49 isolates were non-O157 E. coli while $29(59.1 \%)$ isolates were verotoxin producing non-O157 serotypes. Of the total 29 clinical isolates of non-O157 VTEC were investigated for plasmid profile analysis, twenty-six strains were found to possess plasmid bands, which corresponded to $89.6 \%$ of the total isolates. The number of plasmids varied, ranged from one to four plasmids among the 26 positive isolates. The maximum number of plasmid copies of 4 was recorded in 1 strain; E-HR21. The remaining isolates possessed plasmids with a different number of bands. Among the rest isolates, three plasmids band have been found in 11 strains; E-HR2，E-HR3， E-HR4， E-HR13， E-HR16， EHR17, E-HR20, E-HR22, E-HR23, E-HR24 and EHR25 while two plasmids were found in 7 strains; E-HR1, E-HR5, E-HR6, E-HR10, E-HR11, EHR15, and E-HR18. Seven strains; E-HR7, E-HR8, E-HR9, E-HR12, E-HR14, E-HR19, and E-HR26 possessed only 1 plasmid band. The Figure below shows various plasmids with different molecular weight, ranging from $2.3 \mathrm{~kb}$ to $6.5 \mathrm{~kb}$ (Supercoiled DNA ladder; Fig. 1).

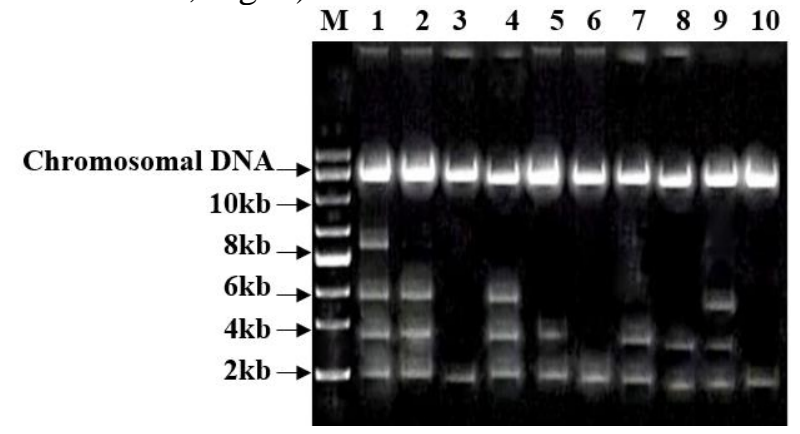

Figure 1. Detection of plasmids among 26 of nonO157 VTEC, M: DNA ladder, Lanes: from 1-10 represent the amplified product. Lane $M$ : standard DNA marker. Lane 1:E-HR21; Lane 2:E-HR2; Lane 3:E-HR7; Lane 4:E-HR13; Lane 5:E-HR15; Lane 6:E-HR19; Lane 7:E-HR18; Lane 8:E-HR10; Lane 9:E-HR22; Lane 10:EHR26.

Among the twenty-six (89.6\%) plasmid positive non-O157 VTEC isolates, 19 isolates possessed plasmids at 3-5years old children while 2 
isolates at 0-1 years old. The occurrence of plasmid producing non-O157 VTEC was significant $(p<0.05)$ among risk factors (age and number of total isolates) distributions $\leq 5$ years old children associated with diarrhea (Table 1).

Table 1. Plasmid profile analysis by source of isolations.

\begin{tabular}{llll}
\hline $\begin{array}{l}\text { Source of } \\
\text { isolation by } \\
\text { age (years) }\end{array}$ & $\begin{array}{l}\text { No. of non- } \\
\text { O157 VTEC } \\
\text { isolates }\end{array}$ & $\begin{array}{l}\text { Plasmid }(+) \\
\text { ve isolates }\end{array}$ & $\begin{array}{l}\text { p- } \\
\text { value }\end{array}$ \\
\hline $0-1$ & 2 & 2 & \\
$1-2$ & 1 & 1 & \\
$2-3$ & 7 & 5 & 0.03 \\
$3-4$ & 11 & 11 & \\
$4-5$ & 8 & 7 & \\
Total & 29 & $26(89.6 \%)$ & \\
\hline
\end{tabular}

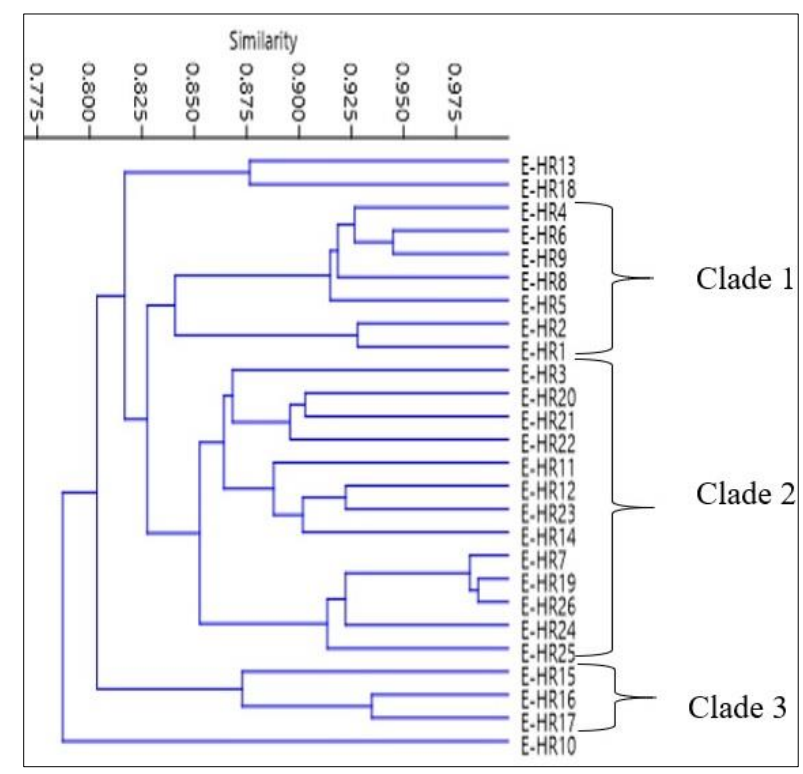

Figure 2. Phylogenetic relatedness among the plasmid positive isolates.
The phylogenetic dendrogram relatedness of 26 non-O157 VTEC isolates was based on the susceptibility of the isolates to antimicrobial agents. Clustering by UPGMA algorithm showed that three clades consistent with similarity coefficients were based on Bray-curtis similarity index. The highest prevalence rate $(50 \%)$ of resistant $E$. coli were distributed in clade 2 followed by $26 \%$ in clade 1 and $12 \%$ in clade 3 , respectively. The remaining $3(12 \%)$ isolates were not in the main clades (EHR13, E-HR18, E-HR10) (Fig. 2). Among the plasmid producing VTEC isolates, it is worth noting that E-HR10 exhibited $100 \%$ resistance to the tested antibiotics while E-HR9, E-HR17 and E-HR24 were $84 \%$ followed by E-HR1, E-HR6, E-HR14 and E-HR $26(80 \%)$. The least resistance was recorded by E-HR3, E-HR11 and E-HR18 (57\%) (Fig. 3).

Amikacin $\quad(30 \mu \mathrm{g})-\mathrm{AMK}, \quad$ Imipenem $(10 \mu \mathrm{g})-\mathrm{IPM}, \quad$ Ciprofloxacin- CIP, Aztreonam $(30 \mu \mathrm{g})$-ATM, Amoxicillin $(25 \mu \mathrm{g})$-AMX, Cefalexin $(30 \mu \mathrm{g})$-CEX.

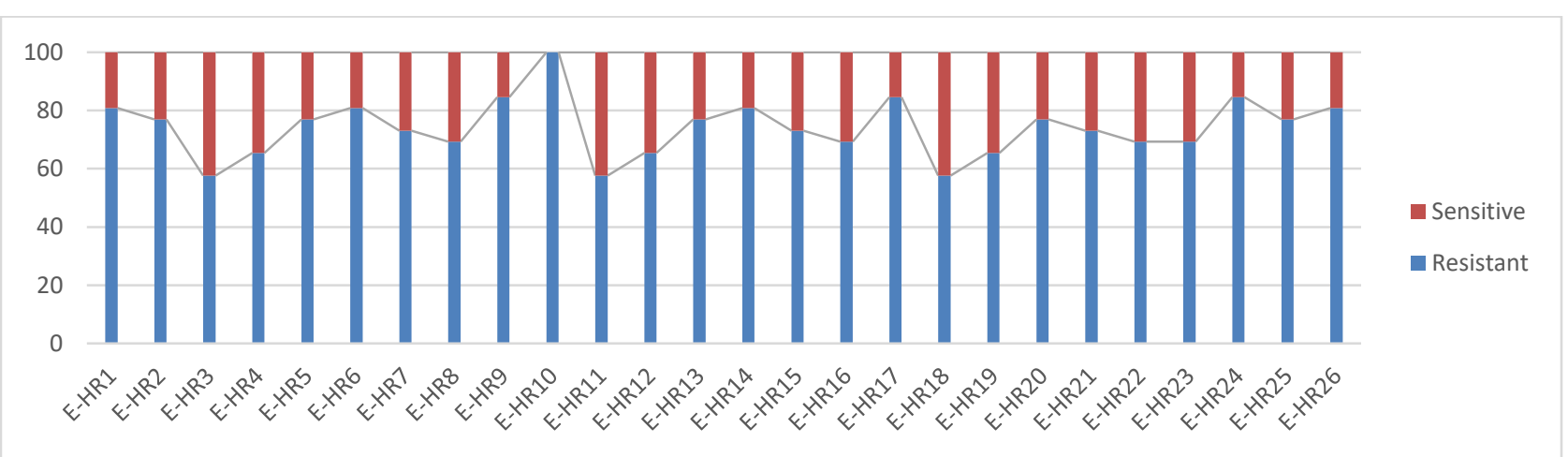

Figure 3. Antibiotic susceptibility patterns of a plasmid containing non-O157 VTEC.

The plasmid number and size varied significantly in 26 non-O157 VTEC isolates. The summary of antibiotic resistance screening tests and antibiogram profiles are presented in Table 2. The results exhibited that all (100\%) of the twenty-sixplasmid containing non-O157 VTEC isolates were multidrug-resistant and harboured plasmids, size between $1.8 \mathrm{~kb}$, and $7.6 \mathrm{~kb}$. The highest number of bands was seen in E-HR21 isolate harboured 4 plasmids ranging $1.8 \mathrm{~kb}$ to $6.6 \mathrm{~kb}$. The remaining isolates had plasmids with different number of bands. Although all these isolates were multidrug- 
resistant, yet resistance patterns were not the same in all cases i.e., variation occurs in antimicrobial resistant patterns. The resistance level, among all the isolates, ranged from four drugs resistance to ten-drug resistance. Interestingly, only three (EHR7, E-HR19 and E-HR26) were resistant to 10 different types of antibiotics (Table 2).

Table 2. Multidrug-resistant of non-O157 VTEC isolates.

\begin{tabular}{cccc}
\hline $\begin{array}{c}\text { Non-O157 } \\
\text { VTEC }\end{array}$ & Resistance patterns & $\begin{array}{c}\text { No. of Plasmid } \\
\text { bands }\end{array}$ & $\begin{array}{c}\text { Plasmid size } \\
(\mathbf{k b})\end{array}$ \\
\hline E-HR1 & AMX, CEX, CIP, MEM & 2 & $5,3.4$ \\
E-HR2 & AMX, CEX, CTX, MEM, IMP, AMK & 3 & $6.6,5,4.6$ \\
E-HR3 & CAZ, CIP, CEX, AMX, ATM & 3 & $6.6,5,4.6$ \\
E-HR4 & AMX, CEX, CTX, MEM, IMP, AMK & 3 & $7.6,6.6,5$ \\
E-HR5 & CAZ, CIP, CEX, AMX, ATM & 2 & $6,4.6$ \\
E-HR6 & AMX, CEX, CIP, MEM, & 2 & $6,4.6$ \\
E-HR7 & AMX, CEX, CTX, ATM, TZP, CAZ, CIP, MEM, IMP, AMK & 1 & 1.8 \\
E-HR8 & CAZ, CIP, CEX, AMX, ATM & 1 & 4.6 \\
E-HR9 & AMX, CEX, CIP, MEM, & 1 & 4.6 \\
E-HR10 & AMX, CEX, CTX, MEM, IMP, AMK & 2 & $6,4.6$ \\
E-HR11 & AMX, CEX, CTX, MEM, IMP, AMK & 2 & $4.6,2$ \\
E-HR12 & CAZ, CIP, CEX, AMX, ATM & 1 & 5.8 \\
E-HR13 & AMX, CEX, ATM, TZP, CAZ, CIP, IMP & 3 & $7.6,6.6,5$ \\
E-HR14 & AMX, CEX, CIP, ATM, MEM, TZP, CAZ & 1 & 5.8 \\
E-HR15 & AMX, CEX, CIP, MEM & 2 & $4.6,2$ \\
E-HR16 & AMX, CEX, ATM, TZP, CAZ, CIP, IMP & 3 & $6.6,5,4.6$ \\
E-HR17 & AMX, CEX, ATM, TZP, CAZ, CIP, IMP & 3 & $6.6,5,4.6$ \\
E-HR18 & AMX, CEX, CTX, MEM, IMP, AMK & 2 & $4.6,2$ \\
E-HR19 & AMX, CEX, CTX, ATM, TZP, CAZ, CIP, MEM, IMP, AMK & 1 & 1.8 \\
E-HR20 & AMX, CEX, CIP, MEM & 3 & $7.6,6.6,5$ \\
E-HR21 & AMX, CEX, CTX, ATM, TZP, CAZ, CIP, MEM, IMP, AMK & 4 & $7.3,4.6,3.4$, \\
E-HR22 & AMX, CEX, CIP, ATM, MEM, TZP, CAZ & 3 & 1.8 \\
E-HR23 & AMX, CEX, CTX, MEM, IMP, AMK & $7.2,5,3.2$ \\
E-HR24 & AMX, CEX, CIP, ATM, MEM, TZP, CAZ & 3 & $7.2,5,3.2$ \\
E-HR25 & AMX, CEX, CTX, MEM, IMP, AMK & 3 & $7.2,5,3.2$ \\
E-HR26 & AMX, CEX, CTX, ATM, TZP, CAZ, CIP, MEM, IMP, AMK & 3 & $7.2,6.6,5$ \\
\hline & & 1 & 1.8 \\
\hline
\end{tabular}

Amoxicillin- AMX; Tazobactam 10/ Piperacillin 75-TZP; Ceftazidime (30 $\mu \mathrm{g})$-CAZ; Imipenem $(10 \mu \mathrm{g})-\mathrm{IPM}$; Cefotaxime $(30 \mu \mathrm{g})$-CTX; Aztreonam $(30 \mu \mathrm{g})$-ATM; Cefalexin $(30 \mu \mathrm{g})$-CEX; Ciprofloxacin-CIP; meropenem-MEM; Amikacin (30 $\mu \mathrm{g})$-AMK.

Plasmid containing non-O157 VTEC isolates suggests that the resistance could be chromosomal, or plasmid-mediated. Plasmid curing tests were performed to decide if the drug resistance was plasmid-mediated. The study has revealed that isolates became sensitive to ampicillin after plasmid curing and suggested that antibiotic resistance could be plasmid-mediated. Different groups of antibiotics (penicillin, fluoroquinolones, aminoglycoside, cephalosporins, carbapenem, and monobactams) were selected for antibiotic susceptibility. Among the 26 isolates of non-O157 VTEC, 8 isolates (EHR3, E-HR5, E-HR7, E-HR10, E-HR14, E-HR19, E-HR21, and E-HR 26) have changed their susceptibility patterns against the tested penicillin group of antibiotic while the rest 14 isolates remain unchanged after curing the plasmid. For the penicillin, three isolates (E-HR7, E-HR19, and EHR26) were cured and became sensitive to the amoxicillin but not to cefalexin, ciprofloxacin, imipenem, and aztreonam while sensitive to amikacin. For the other isolates; E-HR3, E-HR5, EHR10, E-HR14 and E-HR21 remained resistant to amoxicillin but exhibited wider zone of inhibition after plasmid curing. However, all the 8 isolates showed different antimicrobial patterns to amikacin, cefalexin, ciprofloxacin, imipenem, and aztreonam post-curing assay. Three isolates, (E-HR3, E-HR5, E-HR7) were resistant to fluoroquinolones (Ciprofloxacin) after curing of plasmids while initially those isolates were sensitive. Although susceptibility patterns have varied widely and susceptibility patterns were not the same in all isolates, i.e. resistance to certain antibiotics was the same and only few were different. Therefore, this study revealed the loss of resistant properties in cured non-O157 VTEC against amoxicillin (25 $\mathrm{mg} / \mathrm{mL}$ ) as well as to multiple antibiotics (Table 3). 
Table 3. Antibiotic susceptibility patterns of plasmid positive non-0157 VTEC isolates by zones of inhibition (nearest whole millimetre) before and after plasmid curing experiments.

\begin{tabular}{|c|c|c|c|c|c|c|c|c|c|c|c|c|c|c|c|c|c|c|}
\hline \multirow{3}{*}{$\begin{array}{l}\text { Non- } \\
\text { O157 } \\
\text { VTEC }\end{array}$} & \multicolumn{18}{|c|}{ Antibiotics } \\
\hline & \multicolumn{3}{|c|}{ Amoxicillin } & \multicolumn{3}{|c|}{ Cefalexin } & \multicolumn{3}{|c|}{ Ciprofloxacin } & \multicolumn{3}{|c|}{ Amikacin } & \multicolumn{3}{|c|}{ Imipenem } & \multicolumn{3}{|c|}{ Aztreonam } \\
\hline & B & $\mathbf{A}$ & SP & B & $\mathbf{A}$ & SP & B & $\mathbf{A}$ & SP & B & $\mathbf{A}$ & SP & $\mathbf{B}$ & $\mathbf{A}$ & SP & $\mathbf{B}$ & A & SP \\
\hline E-HR 3 & 9 & 11 & $\mathrm{R}$ & 4 & 7 & $\mathrm{R}$ & 18 & $11 * *$ & $\mathrm{R}$ & 5 & 2 & $\mathrm{R}$ & 4 & 6 & $\mathrm{R}$ & 8 & 10 & $\mathrm{R}$ \\
\hline E-HR5 & 7 & 9 & $\mathrm{R}$ & 4 & 6 & $\mathrm{R}$ & 19 & $12 * *$ & $\mathrm{R}$ & 6 & $22^{\wedge}$ & $S$ & 4 & 4 & $\mathrm{R}$ & 16 & $10 * *$ & $\mathrm{R}$ \\
\hline E-HR7 & 4 & $18^{*}$ & S & 3 & 3 & $\mathrm{R}$ & 16 & $8 * *$ & $\mathrm{R}$ & 14 & 17 & $\mathrm{~S}$ & 5 & 7 & $\mathrm{R}$ & 11 & $6 * *$ & $\mathrm{R}$ \\
\hline E-HR10 & 7 & 11 & $\mathrm{R}$ & 4 & 8 & $\mathrm{R}$ & 4 & $10^{\wedge}$ & $\mathrm{R}$ & 6 & 8 & $\mathrm{R}$ & 4 & 8 & $\mathrm{R}$ & 8 & 8 & $\mathrm{R}$ \\
\hline E-HR14 & 5 & 8 & $\mathrm{R}$ & 5 & 7 & $\mathrm{R}$ & 7 & $10^{\wedge}$ & $\mathrm{R}$ & 11 & 15 & $S$ & 2 & 2 & $\mathrm{R}$ & 15 & $9 * *$ & $\mathrm{R}$ \\
\hline E-HR19 & 5 & $18^{*}$ & S & 8 & 4 & $\mathrm{R}$ & 6 & 6 & $\mathrm{R}$ & 15 & 17 & S & 2 & 2 & $\mathrm{R}$ & 8 & $10^{\wedge}$ & $\mathrm{R}$ \\
\hline E-HR21 & 7 & 9 & $\mathrm{R}$ & 7 & 4 & $\mathrm{R}$ & 8 & $4 * *$ & $\mathrm{R}$ & 15 & 19 & S & 10 & 10 & $\mathrm{R}$ & 8 & $10^{\wedge}$ & $\mathrm{R}$ \\
\hline E-HR26 & 4 & $17 *$ & S & 2 & 2 & $\mathrm{R}$ & 6 & $2 * *$ & $\mathrm{R}$ & 15 & 18 & $S$ & 3 & 5 & $\mathrm{R}$ & 8 & 8 & $\mathrm{R}$ \\
\hline
\end{tabular}

B: Before; A: After; *Cured; $\wedge$ More sensitive; $* *$ More resistant; R: Resistant; S: Sensitive; SP: Susceptibility patterns.

Based on gel electrophoresis after postcuring of plasmid, the plasmid copies remained the same in 5 isolates (E-HR3, E-HR5, E-HR10, EHR14, E-HR21) while 3 isolates (E-HR7, E-HR19, and E-HR26) did not harbour any plasmid copies. Plasmid bands were not spotted after the electrophoretic separation of crude (mutant) DNA extracts from three amoxicillin-susceptible mutants. Therefore, this study confirmed that ethidium bromide was able to eliminate all the plasmid bands and resistance properties of the non-O157 VT gene are plasmid mediated (Fig. 4).

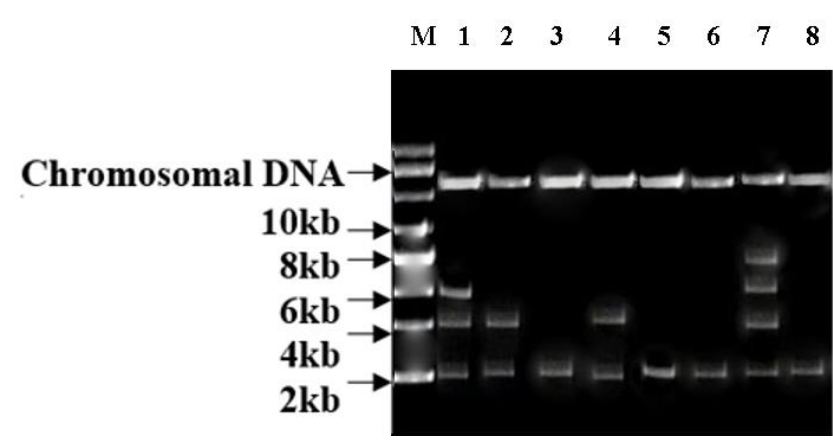

M $1 \begin{array}{llllllll}1 & 2 & 3 & 4 & 5 & 6 & 7 & 8\end{array}$

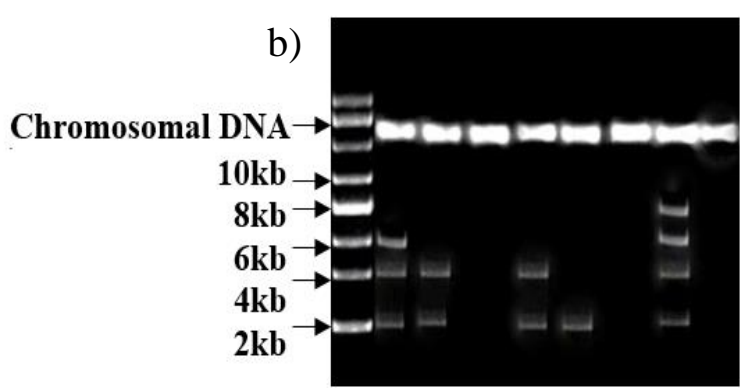

Figure 4. Plasmid curing process of a) pre curing and b) post curing among the non-O157 VTEC; M: DNA ladder, Lanes: from 1-8 represent amplified product. Lane 1: E-HR3; Lane 2: E-HR5; Lane 3: E-HR7; Lane 4: E-HR10; Lane 5: E-HR14; Lane 6: E-HR19; Lane 7: E-HR21; Lane 8: E-HR26.

In terms of the post plasmid curing phylogenetic relatedness, the dendrogram of clustering by UPGMA algorithm based on similarity coefficient showed the consistent distribution in some cases. The distribution was consistent among the antimicrobial susceptibility patterns and several plasmid bands of non-O157 VTEC isolates. Among the 8 isolates, 3 strains (EHR7, E-HR19, and E-HR26) harboured 1 plasmid band in clade 1 while in clade 2 , each isolate (EHR3, E-HR5, and E-HR10) harboured 3, 2 and 2 plasmids respectively. Three isolates (E-HR7, EHR19 and E-HR 26) exhibited similarity based on plasmid analysis and antimicrobial susceptibility patterns. E-HR14 isolates have no phylogenetic relationship with other groups of plasmids containing non-O157 VTEC isolates (Fig.5). 


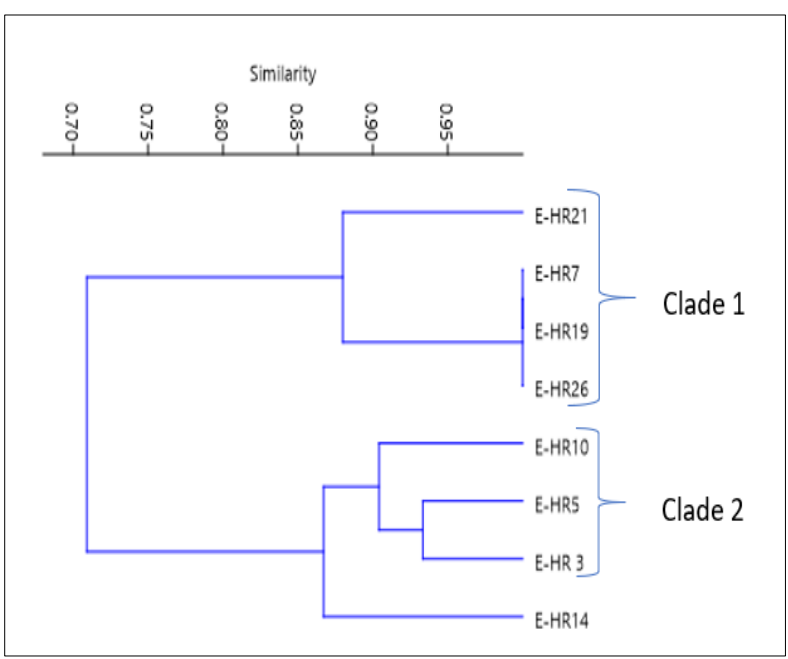

Figure 5. Phylogenetic relatedness.

Of the total 26 plasmids containing nonO157 VTEC isolates, 8 isolates (E-HR3, E-HR5, EHR7, E-HR10, E-HR14, E-HR19, E-HR21, and EHR26 showed variation in susceptibility patterns aligned with different plasmid size and bands significantly. This observation was considered encouraging as it suggests that the presence of VT gene could be plasmid-mediated. In this study, purified plasmid was used as DNA template for polymerase chain reaction (PCR). Based on gel electrophoresis, 3 isolates (E-HR7, E-HR19, and EHR26) were VT positive. VT1 and VT2 genes amplified with $348 \mathrm{bp}$ and $584 \mathrm{bp}$, respectively. The remaining 5 isolates were VT negative (Fig. 6).



Figure 6. Plasmid-mediated non-0157 VTEC. M: DNA ladder, Lanes: from 1-9 represent amplified product (348 bp and $584 \mathrm{bp}$ ). Lane 1: positive control; Lane 2:E-HR3; Lane 3:E-HR5; Lane 4:E-HR7; Lane 5:E-HR10; Lane 6:EHR14; Lane 7:E-HR19; Lane 8:E-HR21; Lane 9:E-HR26.

\section{Discussion:}

Pathogenic isolates of non-O157 VTEC have a comparatively high potential for developing resistance. Besides, resistance genes can be associated with mobile DNA plasmids which facilitate genetic materials to the same species and as well as to bacteria in another genus or species (21). Indeed, the flow of genetic materials between and within the genomes in bacteria is extensive and well established (22).

This study has revealed that three isolates (E-HR7, E-HR19, and E-HR26) were sensitive to penicillin while resistance to other antibiotic but remain sensitive to amikacin (aminoglycoside). A possible contributory factor such as plasmid curing is a chemical treatment in cells. The effectiveness of the curing agents varies, and the variation depends on the curing agent and microorganism being cured. Ethidium bromide was used according to Zaman et al., (18) which is also supported by El-Deep et al., (23) for plasmid curing among $E$. coli isolates.

Variation in the plasmid profile among the investigated isolates of non-O157 VTEC proposes their diversity. Recent studies of Dadi et al., (24) and Ineta et al., (15) have shown agreement with these findings where a wide range of distinct plasmid profiles was found among the tested organisms. In this study, all the clinical isolates of non-O157 VTEC possessed molecular size ranging from $1.8 \mathrm{~kb}$ to $7.6 \mathrm{~kb}$. Besides, all the plasmids containing isolates that are multidrug resistance, can cause disease with hard treatment. In this context, Gomes et al., have reported that the large virulence plasmid in non-O157 VTEC causes numerous diseases (25). In addition, various microorganisms are continuously exposed to hospital environment, and their resistance increases as a function of time due to exposure to many factors. Moreover, bacteria acquire resistance through natural or intrinsic resistance. Multiple mechanisms of antibiotic are responsible for resistance such as multidrug efflux, drug inactivation, drug target alteration, reduction of permeability or uptake, extrachromosomal or acquired resistance $(7,26,27)$. These contributory factors rise the global dissemination of MDR bacteria. The fast dissemination of antibiotic resistances demands effective means to stop or slow down. Thus, the studies confirmed the important role of plasmids number and size on resistance characteristics in non-O157 VTEC.

Plasmid curing was confirmed by agarose gel electrophoresis and showed that the, cells treated with ethidium bromide, are able to exclude all the plasmid bands in some isolates. Among the curing agents, ethidium bromide was more effective compared to others such as sodium dodecyl sulfate, and acridine orange (18). In this study, treatment with ethidium bromide followed by sub-lethal concentration of antibiotic; penicillin (amoxicillin) selection resulted in the more effective curing process. The plasmid curing process is rapid, simple 
and sufficient for a wide range of $E$. coli and other bacterial species $(15,18,28)$ but yet to observe agents to eliminate all plasmids from different host (29). The Plasmids loss in cured strains resulted in the vanishing of the outer membrane components as well as changes in the thickness peptidoglycan layer. In case of large plasmid, it can be correlated with the loss of amoxicillin resistance. Generally, curing efficacy can be confirmed by the physical loss of plasmid (30). However, the effectiveness of curing methods depends on the nature of the bacterial host and plasmids, where some may work better than the others or some may not. Plasmid interference for curing antibiotic resistant therapy other than ethidium bromide could be a possible simple oral administrative route against the threat of multidrug-resistant.

A further variation was observed in plasmid analysis, and antimicrobial susceptibility, and similarity coefficients by phylogenetic grouping after the post plasmid curing isolates. Additional factors might be contributory reasons for different plasmid size and bands. Plasmid producing multidrug-resistant non-O157 VTEC isolates exhibits high molecular weights and higher resistant to antibiotics. Also, some of the isolates after plasmid curing continued to be resistant to multiple antibiotics. These could be due to the presence of multiple resistant genes in bacteria, which could be transferred to not only through the same species but also to others. So, the presence of multiple bands with varying size in DNA plasmid has been characterized in terms of their antimicrobial resistance (15).

Currently, extended-spectrum $\beta$-lactamases (ESBL), AmpC $\beta$-lactamase (pAmpC) bla $a_{\mathrm{CMY}-2}$, carbapenemases $b l a_{\mathrm{NDM}-1}, b l a_{\mathrm{OXA}-48}, \quad$ and $b l a_{\mathrm{KPC}-2}$ described as plasmid-mediated resistance mechanisms are increasing in E. coli (31-32). This study reveals that the emergence of plasmidmediated verotoxin gene (PMVT) resistance can also be developed through horizontal gene transfer and can co-exist on the same plasmid and may able to transfer to recipients. The association between the resistant phenotypes and plasmid replicons has been tested while accounting for phylogenetic similarity for each trait. Besides, PCR assay confirmed that VT1 and VT2 genes were amplified at $348 \mathrm{bp}$ and 584bp respectively, and the bacterial genome sequence analysis aligned with VT1 and VT2 genes. Analysis of bacterial genome sequences and horizontally transferred plasmids highlighted the presence of plasmid-mediated VT gene in nonO157 E. coli isolates.

\section{Conclusion:}

The existence, and prevalence of bacterial antibiotic resistance are continuing, and critically ill patients at the hospital are at high risk of being infected. This study highlights that the clinical isolates resistant to multiple antibiotics aligned with different plasmid number and size could be a possible carrier for VT gene. More importantly, VT gene is closely related to various antibiotics belonging to the transmissible plasmids. As a whole, this study confirms the presence of VT gene in clinical isolates of non-O157 E. coli which might complicate the antimicrobial resistance scenario throughout the world. The findings of this study provide an additional knowledge to the global literature on plasmid-mediated VT gene in nonO157 E. coli. It can be recommended that more attention should be paid to the surveillance of plasmid-mediated VT gene. To the best of our knowledge, this is the first report in the global literature on plasmid-mediated VT gene in nonO157 E. coli. Therefore, a systematic screening policy should be implemented for rapid detection of the plasmid-mediated multidrug-resistant isolates to prevent the horizontal gene transfer associated with effective curing to avoid dissemination of VT gene in the future.

\section{Acknowledgments:}

We are grateful to Universiti Malaysia Pahang and Hospital Tengku Ampuan Afzan, Kuantan, Pahang, Malaysia for research facilities. We express sincere gratitude to the Medical Research \& Ethics Committee (MREC), Ministry of Health, Malaysia.

\section{Authors' declaration:}

- Conflicts of Interest: None.

- We hereby confirm that all the Figures and Tables in the manuscript are mine ours. Besides, the Figures and images, which are not mine ours, have been given the permission for republication attached with the manuscript.

- The author has signed an animal welfare statement.

- Ethical Clearance: The project was approved by the local ethical committee in University Malaysia Pahang.

\section{References:}

1. Fazlul M, Rashid SS, Nazmul M, Zaidul I, Baharudin R, Nor A. A clinical update on antibiotic resistance gram-negative bacteria in Malaysia-a review. IJPR. 2018; 45: 270-283.

2. World Health Organization. E. Coli. [Internet]. 2018 [cited 2019 July 16]; Available from: 
https://www.who.int/news-room/fact-sheets/detail/ecoli.

3. Conrad C, Stanford K, McAllister T, Thomas J, Reuter T. Shiga toxin-producing escherichia coli and current trends in diagnostics. Animal Frontiers. 2016; 6(2): 37-43. DOI: 10.2527/af.2016-0021.

4. Peirano V, Bianco MN, Navarro A, Schelotto FV, Arela G. Diarrheagenic escherichia coli associated with acute gastroenteritis in children from soriano, uruguay. Can J Infect Dis Med Microbiol. 2018; 2018.

5. Bai X,Hu B,Xu Y,Sun H,Zhao A, Ba P, et al. Molecular and phylogenetic characterization of nono157 shiga toxin-producing escherichia coli strains in china. Front Cell Infect Microbiol. 2016; 6: 143-143. DOI: $10.3389 /$ fcimb.2016.00143.

6. Li Q, Chang W, Zhang H, Hu D, Wang X. The role of plasmids in the multiple antibiotic resistance transfer in esbls-producing escherichia coli isolated from wastewater treatment plants. Front. Microbiol. 2019; 10(633) DOI: 10.3389/fmicb.2019.00633.

7. Sultan I, Rahman S, Jan AT, Siddiqui MT, Mondal AH, Haq QMR. Antibiotics, resistome and resistance mechanisms: A bacterial perspective. Front Microbiol. 2018; 9: 2066-2066. DOI: 10.3389/fmicb.2018.02066.

8. San M A. Evolution of plasmid-mediated antibiotic resistance in the clinical context. Trends Microbiol. 2018; 26(12): 978-985. DOI: https://doi.org/10.1016/j.tim.2018.06.007.

9. Rozwandowicz M, Brouwer MSM, Fischer J, Wagenaar JA, Gonzalez-Zorn B, Guerra B, et al. Plasmids carrying antimicrobial resistance genes in enterobacteriaceae. J. Antimicrob. Chemother. 2018; 73(5): 1121-1137. DOI: 10.1093/jac/dkx488.

10. Partridge SR, Kwong SM, Firth N, Jensen SO. Mobile genetic elements associated with antimicrobial resistance. Clin Microbiol Rev. 2018; 31(4): e00088-17.

11. Li BW, Ebster TJ. Bacteria antibiotic resistance: New challenges and opportunities for implant-associated orthopedic infections. J Orthop Res. 2018; 36(1): 2232. DOI: 10.1002/jor.23656.

12. Fazlul M, Zaini M, Rashid M, Nazmul M. Antibiotic susceptibility profiles of clinical isolates of Pseudomonas aeruginosa from Selayang hospital, Malaysia. Biomed Res. 2011; 22(3).

13. Fazlul MKK, Farzana Y, Najnin A, Rashid MA, Nazmul MHM. Detection of ctx-m-type esbls from Escherichia coli clinical isolates from a tertiary hospital, Malaysia. Baghdad Sci J. 2019; 16(3): 682688. DOI: 10.21123/bsj.2019.16.3(Suppl.).0682.

14. Maziz MNH, Hussaini J, Khan MFK. Antibiotic susceptibility profiles of clinical isolates of Acinetobacter species isolated from Selayang hospital, Malaysia. IJID. 2012; 16: e424. DOI: 10.1016/j.ijid.2012.05.589.

15. Ineta BE, Madu EP, Abdulhadi AS, Ibrahim HI. Antibiotic susceptibility and plasmid profile of clinical isolates of Escherichia coli. Biomedical Research. 2018 Oct 5;29(17).
16. Nazmul M, Fazlul M, Rashid SS, Doustjalali SR, Yasmin F, Al-Jashamy K, et al. Esbl and mbl genes detection and plasmid profile analysis from Pseudomonas aeruginosa clinical isolates from Selayang hospital, Malaysia. Pak J Med Health Sci. 2017; 11(3): 815-818.

17. Bauer AW, Kirby WM, Sherris JC, Turck M. Antibiotic susceptibility testing by a standardized single disk method. Am. J. Clin. Pathol. 1966; 45(4): 493-496.

18. CLSI. Performance Standards for Antimicrobial Susceptibility Testing. CLSI supplement M100. $27^{\text {th }}$ Edition, Published by Wayne, PA: Clinical and Laboratory Standards Institute. 2017.

19. Cebula TA, Payne WL, Feng P. Simultaneous identification of strains of Escherichia coli serotype o157:H7 and their Shiga-like toxin type by mismatch amplification mutation assay-multiplex pcr. J Clin Microbiol. 1995; 33(1): 248-50.

20. Van H A, Mevius D, Guerra B, Mullany P, Roberts A, Aarts H. Acquired antibiotic resistance genes: An overview. Front Microbiol. 2011; 2(203) DOI: 10.3389/fmicb.2011.00203.

21. Pinilla-Redondo R, Cyriaque V, Jacquiod S, Sørensen SJ, Riber L. Monitoring plasmid-mediated horizontal gene transfer in microbiomes: Recent advances and future perspectives. Plasmid. 2018; 99: 56-67. DOI: https://doi.org/10.1016/j.plasmid.2018.08.002.

22. El-Deeb N, Sharaf M, El-Adawi H. Antibacterial and plasmid curing activity of lactic acid bacteria against multidrug resistant bacteria strains. Int $\mathrm{J}$ Pharm. 2015; 11(2): 114-121.

23. Dadi BR, Abebe T, Zhang L, Mihret A, Abebe W, Amogne W. Drug resistance and plasmid profile of uropathogenic escherichia coli among urinary tract infection patients in addis abeba. J Infect Dev Countr. 2018; 12(08): 608-615.

24. Gomes TAT, Elias WP, Scaletsky ICA, Guth BEC, Rodrigues JF, Piazza RMF, et al. Diarrheagenic escherichia coli. Braz J Microbiol. 2016; 47: 3-30. DOI: https://doi.org/10.1016/j.bjm.2016.10.015.

25. Nelson DW, Moore JE, Rao JR Antimicrobial resistance (amr): Significance to food quality and safety. Food Quality and Safety. 2019; 3(1): 15-22. DOI: $10.1093 /$ fqsafe/fyz003.

26. Khan MFK, Rashid SS, Ramli ANM, Ishmael UC, Maziz MNH. Detection of Esbl and Mbl in Acinetobacter spp. and their plasmid profile analysis. JJBS. 2019; 12(3).

27. Patwardhan RB, Dhakephalkar PK, Chopade BA, Dhavale DD, Bhonde RR. Purification and characterization of an active principle, lawsone, responsible for the plasmid curing activity of plumbago zeylanica root extracts. Front Microbiol. 2018; 9 : 2618-2618. DOI: 10.3389/fmicb.2018.02618.

28. Williams LE, Wireman J, Hilliard VC, Summers AO. Large plasmids of Escherichia coli and Salmonella encode highly diverse arrays of accessory genes on common replicon families. Plasmid. 2013; 69(1): 3648.

DOI:

https://doi.org/10.1016/j.plasmid.2012.08.002. 
29. Buckner MMC, Ciusa ML, Piddock LJV. Strategies to combat antimicrobial resistance: Anti-plasmid and plasmid curing. FEMS Microbiol Rev. 2018; 42(6): 781-804. DOI: 10.1093/femsre/fuy031.

30. Liu X, Liu H, Li Y, Hao C. High prevalence of $\beta$ lactamase and plasmid-mediated quinolone resistance genes in extended-spectrum cephalosporin-resistant escherichia coli from dogs in shaanxi, China. Front. Microbiol. 2016; 7(1843) DOI: 10.3389/fmicb.2016.01843.
31. Liu X, Thungrat K, Boothe DM. Occurrence of OXA48 Carbapenemase and other $\beta$-lactamase genes in Esbl-producing multidrug resistant escherichia coli from dogs and cats in the United States, 2009-2013. Front. Microbiol. 2016; 7: 1057.

32. Wen Y, Pu X, Zheng W, Hu G. High prevalence of plasmid-mediated quinolone resistance and incq plasmids carrying QNRS2 gene in bacteria from rivers near hospitals and aquaculture in China. PLoS One. 2016; 11(7): e0159418. DOI: 10.1371/journal.pone.0159418.

\section{التوصيف الجزيئي لبكتريا الإشريكية القولونية بخلايا O157 بوساطة البلازميد المعزولة من الرضع والأطفال المصابين بالإسهال المبال}

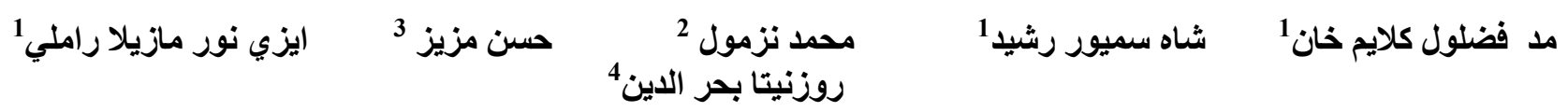

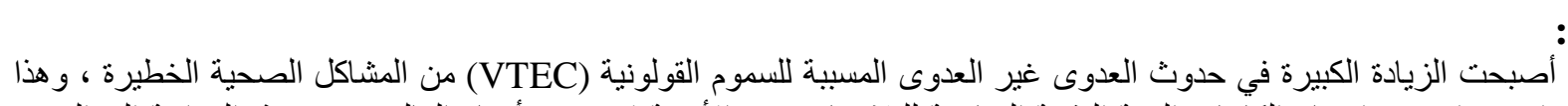

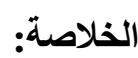

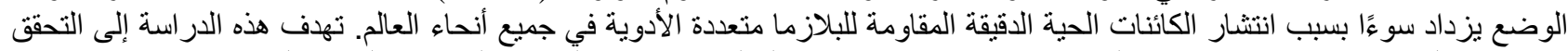

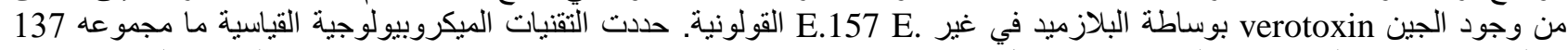

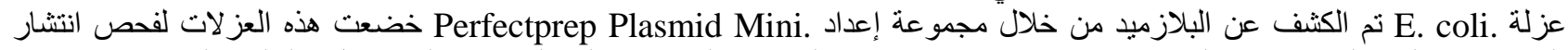

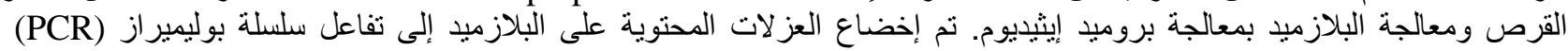

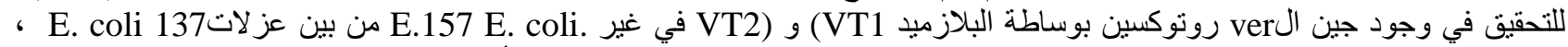



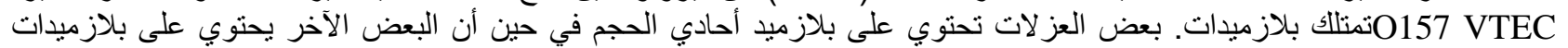

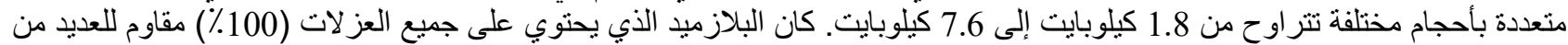

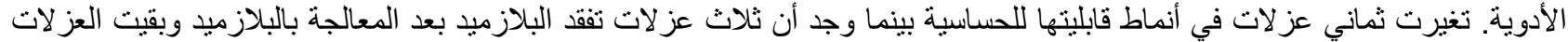



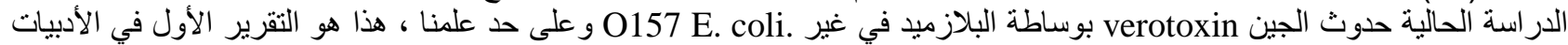

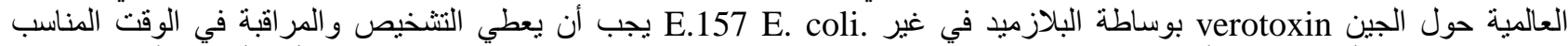
للعدوى VTEC الأولوية لوقف أو إبطاء الجين للنشر عن طريق انتقال الجين بوساطة البلازميد بين نفس البكتيريا أو الأنو أع الأخرى.

$$
\text { الكلمات المفتاحية: الإسهال، ماليزيا، غير القولونية O157 E. coli ، البلازميد، الفيروكسين. }
$$
}

